\title{
KEARIFAN LOKAL MASYARAKAT PERMUKIMAN SAWOJAJAR KECAMATAN KEDUNGKANDANG, KOTA MALANG
}

\author{
Bhaga Aninditatama \\ Magister Arsitektur, Universitas Brawijaya Malang \\ Aghardc58@gmail.com
}

\section{Abstrak}

Kata Kunci: Malang, Kearifan Lokalitas, Arsitektur Indonesia, Kearifan Arsitektur, Sawojajar

Sawojajar merupakan permukiman warga yang luas, permukiman ini terletak di kota malang, tepatnya di kecamatan kedungkandang bersebelahan dengan kecamatan kelojen dan di batasi oleh kabupaten malang. Permukiman yang berada di sebelah timur kota malang merupakan pernukiman padat penduduk yang paling besar dii malang, mengakibatkan beberapa aspek-aspek sosial-ekonomi yang berdampak pada lingkungan sekitar permukiman, hal ini terjadi di karenakan semakin banyaknya kebutuhan manusia yang setiap tahunnya selalu bertambah dan bervariatif, karena pertumbuhan penduduk inilah sawojajar pada tahun 2010 beralihfungsi lahan menjadi kawasan pertokoan, hal inilah yang menjadi daya tarik kuat mengapa permukiman ini sangat menarik untuk dikaji kearifan lokalnya, metode yang digunakan adalah pengamatan lebh lanjut di area tersebut dan mencari keunikan kawasan ini digali dari aspek fisik dan non-fisiknya serja mengagaskan perubahan tersebut dan memperoleh kearifan lokal yang terdapat di permukiman sawojajar.
\end{abstract}

Key Words: Malang, Wisdom locality, Architecture of Indonesia, wisdom, Sawojajar

\begin{abstract}
Sawojajar is the settlement of a broad settlement is located in the city of malang, exactly in the sub-district kelojen kedungkandang adjacent to and in the limit by malang regency. The settlement is located in the east of the city of Malang is a densely populated pernukiman that most termed Dii malang, resulted in some aspects of the socio-economic impacts on the environment around the settlement, this happens in karenakan the increasing number of human need that every year increases and bervariatif, because this is the sawojajar population growth in 2010 switches the function of the land to the area shops, this becomes the strong appeal why the settlement was very interesting to be examined local wisdom, the method used is the observations more information in the area and seek the uniqueness of this area was drawn from the aspects of the physical and non-physical and concluded the changes and obtain local wisdom found in settlements sawojajar.
\end{abstract}




\section{Kearifan Lokal Masyarakat Permukiman Sawojajar Kecamatan Kedungkandang, Kota Malang \\ Bhaga Aninditatama}

\section{Pendahuluan}

Awalnya kawasan sawojajar adalah permukiman warga yang mayoritas adalah petani dan berkebun. Namun karena produktivitas yang terus meningkat maka dibentuklah sebuah lahan tambahan yang dulunya adalah sebuah lahan kosong menjadi lahan pertokoan. Pada aktivitas ini terbentuk ruang komunal yaitu ruang yang terjadi karena persepsi manusia untuk berinteraksi, yang pembentukannya dilatar belakangi oleh persamaan aktivitas dan dipengaruhi oleh kondisi setting lingkungan fisik, organisasi ruang, layout bangunan dan tuntutan atribut ruang.

Menurut kajian yang didapat bahwa sawojajar ini memiliki banyak fasilitas pendukung permukiman, antara lain banyaknya fasilitas pendidikan yaitu SD,SMP, dan SMA, fasilitas penunjang berupa supermarket Giant di bagian gerbang masuk sebelah selatan di permukiman sawojajar. Serta banyaknya fasiliatas barang dan jasa yang berada di lingkungan tersebut. Di tahun 2010 tidak sedikit permukiman warga dan komplek-komplek penduduk yang hanya sekedar rumah tinggal dan sedikitnya toko-toko dan bangunan rumah toko yang berada pada tahun 2010

Dengan adanya penduduk baru ini faktor apa sajakah yang membuat perubahan yang mempengaruhi perkembangan yang ada di lingkungan sawojajar ini?, apakah perubahan itu membuat pola ruang yang berbeda di lingkungan sawojajar tersebut?.

\section{LOKASI STUDI}

Lokasi penelitian terletak di permukiman sawojajar, kecamatan kedungkandang, kota malang,adapun memilih lokasi studi ini yaitu pesatnya pertumbuhan sosial dan ekonomi masyarakat sekitar, memiliki potensi-potensi pertokoan yang cukup banyak, pada dasarnya di tahun 2000 permukiman warga sawojajar ini di peruntukan untuk menjadi permukiman warga pendatang dan oleh pemborong wilayah ini merupakan tempat hunian paling luas di kota malang. Saat tahun 2012 perubahan ini terjadi dimana mulai banyaknya pengalihan fungsi lahan menjadi pertokoan yang sangat luas persebarannya sehingga membuat $60 \%$ dari permukiman padat penduduk ini menjadi lahan pertokoan.

\section{Pembahasan}

1. Bahasa

Sistem bahasa yang biasa digunakan oleh warga sawojajar ada dua bahasa yaitu Bahasa Jawa dan Bahasa Indonesia. Antar masyarakat menggunakan Bahasa Jawa dalam proses interaksi dalam kehidupan sehari-hari. Karena mayoritas penduduk di sawojajar adalah pedagang mereka berinteraksi dari rumah ke rumah untuk berkomunikasi, adapula penduduk yang bukan asli malang di permukiman ini sehingga antar penduduk berkomunikasi menggunakan bahasa indonesia.

\section{Organisasi}

Permukiman sawojajar terdiri dari 2 bagian Yaitu perumahan sawojajar 1 dan perumahan sawojajar 2, pada permukiman penduduk ini terdapat sejumlah 30.931 dengan luasan tapak permukiman sepanjang 1,81 km², Dalam menjalankan tugas pemerintahan di wilayahnya, Kelurahan Sawojajar memiliki mitra kerja. Mulai dari bidang pendidikan, kesehatan masyarakat, ekonomi masyarakat, keamanan dan ketertiban, partisipasi masyarakat, pemerintahan, lembaga masyarakat, hingga pemberdayaan kesejahteraan keluarga. Selain itu, ada organisasi sosial kemasyarakatan seperti karang taruna, karang werda, kader lingkungan, PSM (Pekerja Sosial Masyarakat), Gapoktan (Gabungan Kelompok Tani dan Nelayan), KKB (Kader Keluarga Berencana), BKB (Bina Keluarga Balita), WKSBM (Wahana Kesejah- 
teraan Sosial Berbasis Masyarakat), Tokoh Masyarakat, Gerdu Taskin, PLKB, Dasawisma, PAUD (Pendidikan Anak Usia Dini), TK, Modin, Satgas Linmas, dan lain-lain.

3. Pengetahuan

Awalmula penduduk di sawojajar ini mereka adalah sebagai petani dan berkebun, masih terdapat mitra kerja dalam bidang hal ini, seiring berjalannya waktu, mayoritas penduduk ini memilih menjadi pedagang dan memiliki toko, didukung oleh adanya fasilitas pendidikan berupa banyaknya SD,SMP,SMK dan Universitas Wisnuwardana di lingkungan sawojajar bertambahnya sejumlah toko,minimarket dan toko penjual alat tulis yang diperlukan para siswa dan juga mahasiswa melakukan kegiatan di lingkungannya. Sedangkan penduduk juga memiliki toko sendiri di area teras rumah untuk menambah pendapatan selain dari tempat ia bekerja.
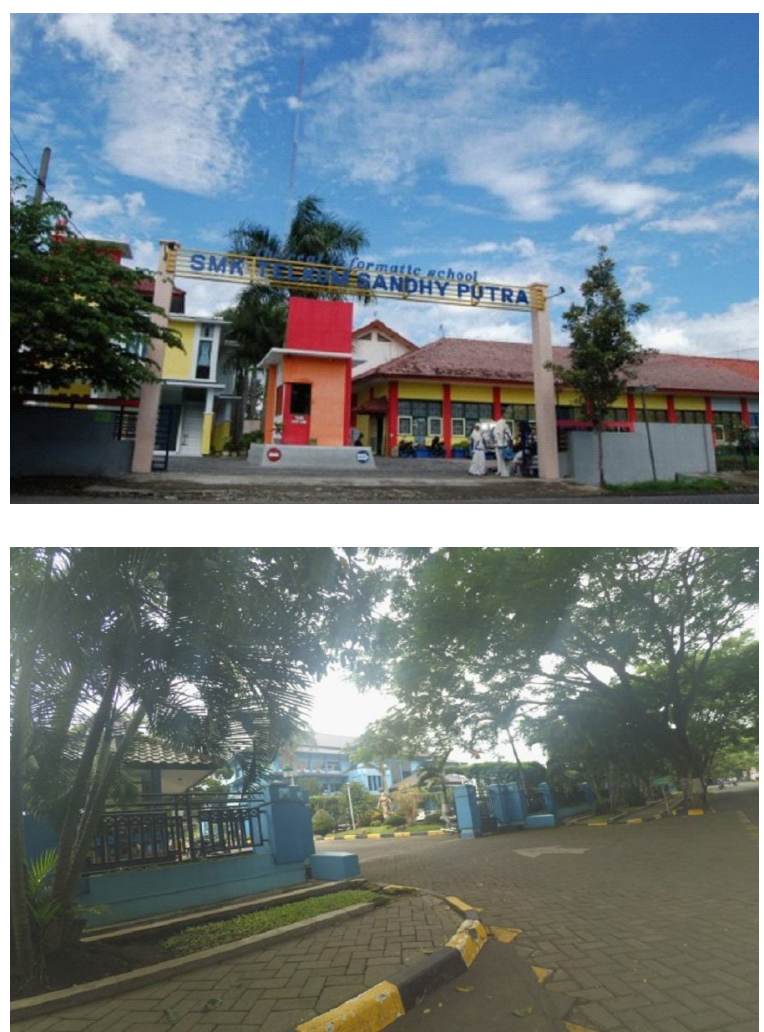

4. Mata Pencaharian

Di tahun 2003 penduduk sekitar masyarakat sawojajar ini sebagai pertani dan berkebun, lahan-lahan pun mulai menjadi permukiman di tahun 2006 sehingga lahan-lahan yang terdapat banyak sawah menjadi deretan permukiman warga sekitar, dilain sisi adanya pengaruh lingkungan di sawojajar ini membuka toko kecil dan toko kebutuhan seharihari (mini market), keadaan ini karena adanya fasilitas pendidikan dan jasa lain di permukiman ini. Di tahun 2010 lahan yang di desain menjadi sebuha permukiman di kota malang kini sudah beralih menjadi pertokoan dan banyaknya ruko di tahun 2016, sehingga sampai saat ini bermunculan komplek-komplek ruko baru di pinggiran lingkungan permukiman sawojajar semabagai mata pencaharian penduduk sekitar.
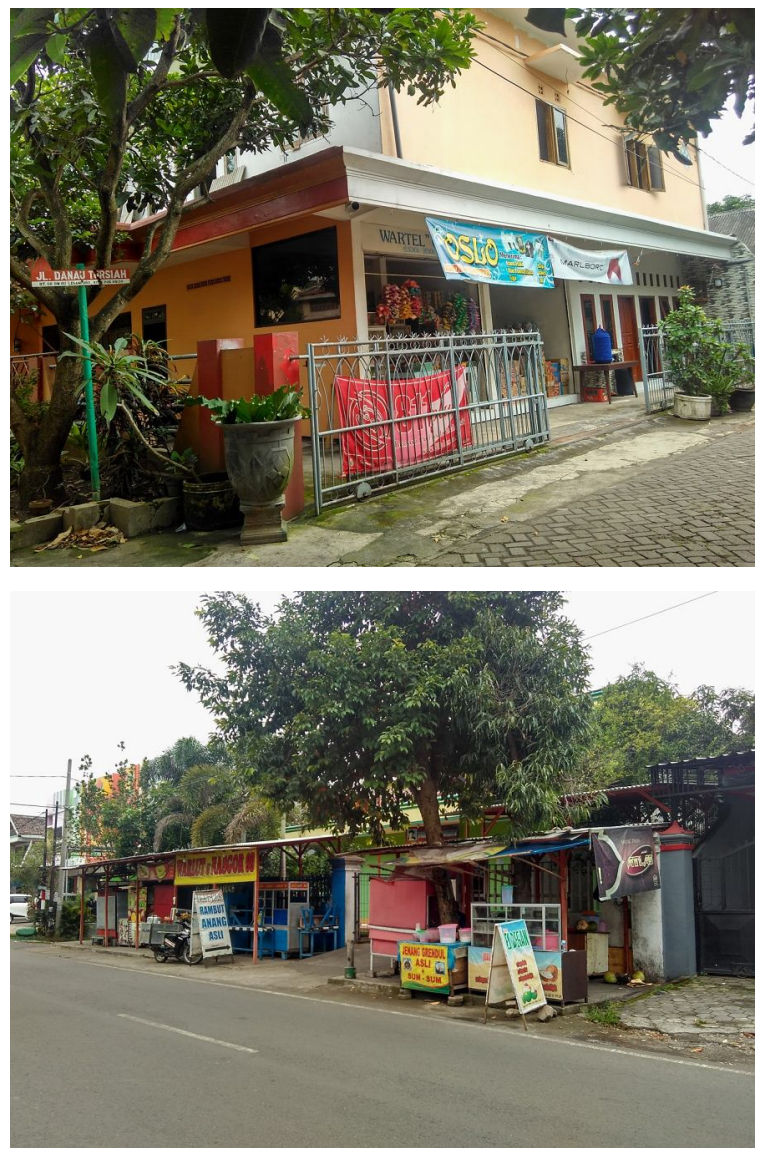
5. Agama

Mayoritas penduduk di permukiman sawojajar beragama islam, terdapat 3 buah masjid besar dan sebanyak lebihdari 20 mushola terdapat di lingkungan permukiman di sawojajar.
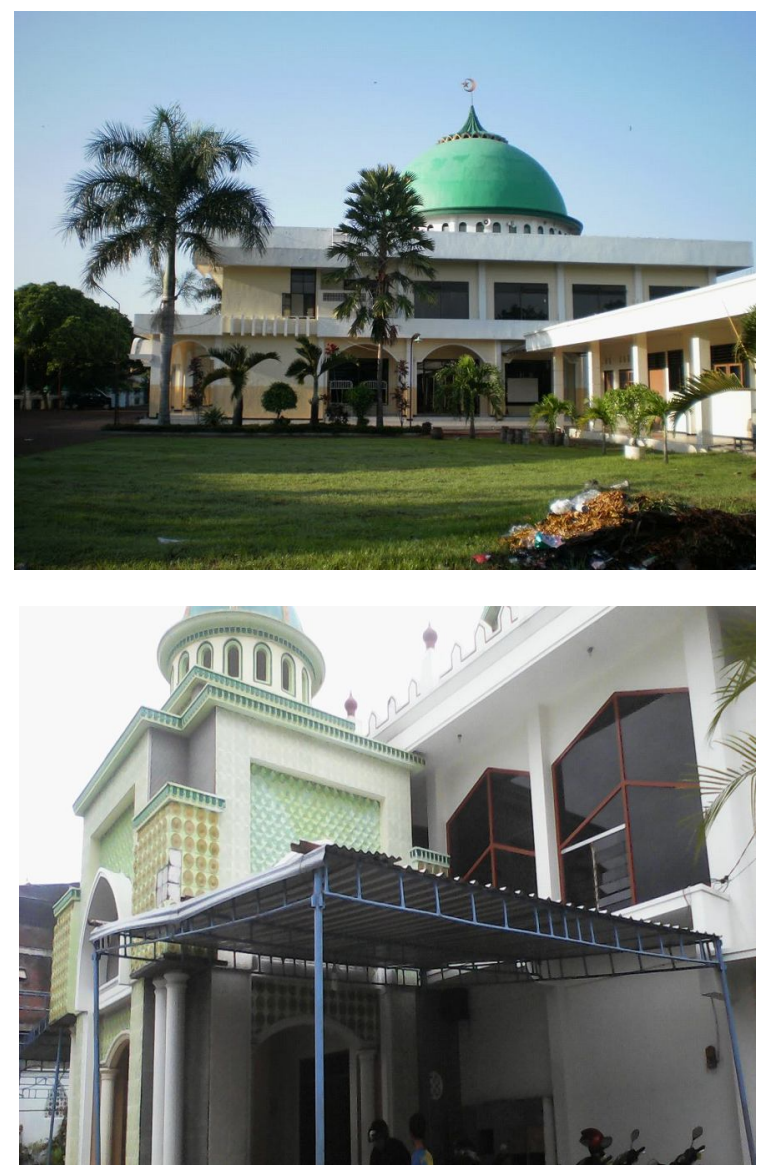

6. Kesenian

Terdapat sebuah sanggar seni tari yang membuka kursus menari tradisional beserta kelompok pemain gamelan (karawitan). Nama sanggar ini adalah Sanggar Seni Tari dan Reog Sardulo Djojo. Budaya yang terbentuk di permukiman ini terjadi turun temurun sehingga menjadi suatu wadah kreatifitas penduduk sekitar untuk menanamkan nilai budaya pada setiap generasi ke generasi

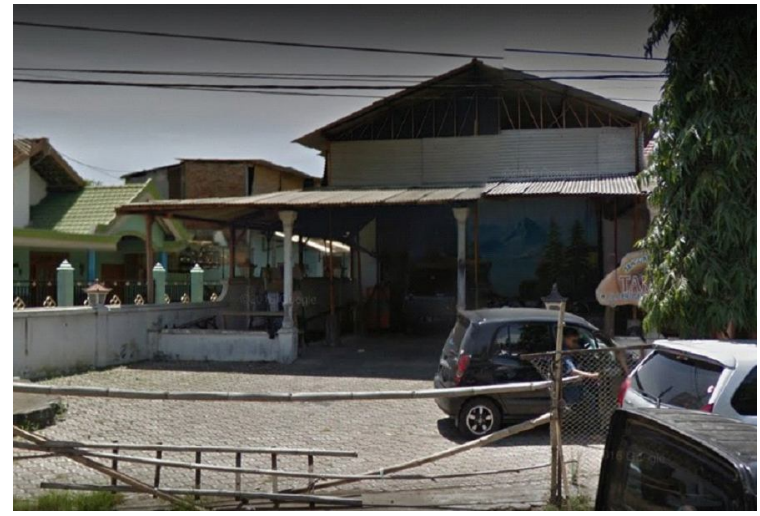

\section{Kearifan Lokal Pada Skala Mikro}

a. Pola Ruang pada rumah

pola ruang rumah yang terdapat di lingkungan sawojajar ini tidak lepas dari kearifan lokal setempat, pola ruang pekerja juga merupakan dampak dari tradisi dan penanganan warga setempat untuk kenyamanan dan keamanan agar bersosialisasi dengan pembeli dan penghuni lain bisa berjalan dengan lancar. Penataan atau pola yang terbentuk terjadi dibeberapa sisi rumah agar pola ruang menjadi standar dari keinginan penghuni rumah itu sendiri.

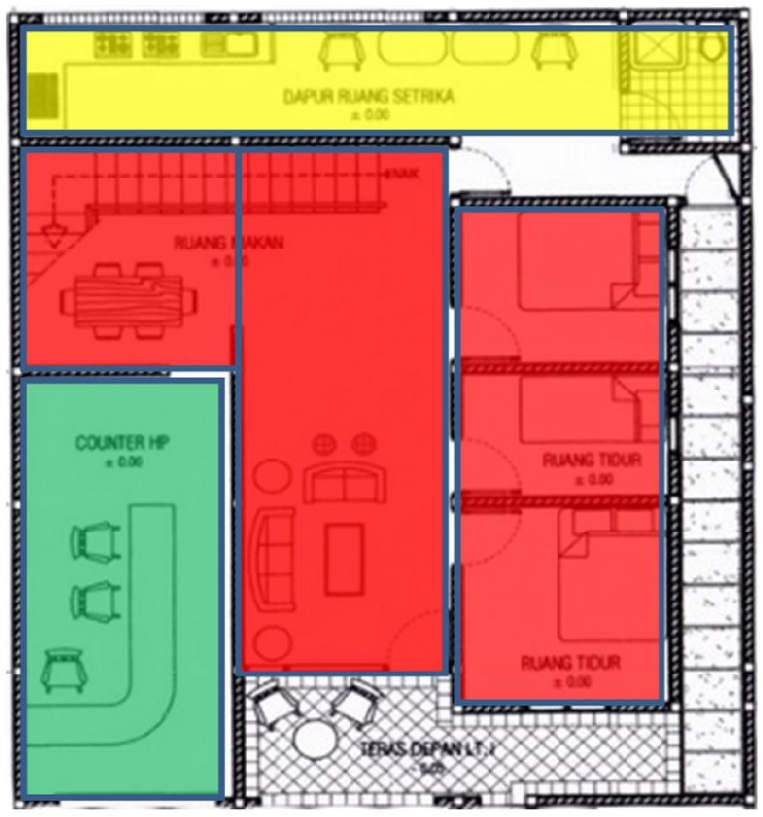


b. Sosial - Ekonomi

Sosial masyarakat sekitar mayoritas adalah penduduk yang bekerja di pusat kota malang, hal ini terlihat padatnya jalanan di sawojajar pada pagi, siang dan sore hari, dimana banyaknya pendudukyang hanpir seluruhnya berangkat kerja dan ada pula yang hanya menjaga toko yang memiliki bangunan toko dirumah atau di dekat ia tinggali.
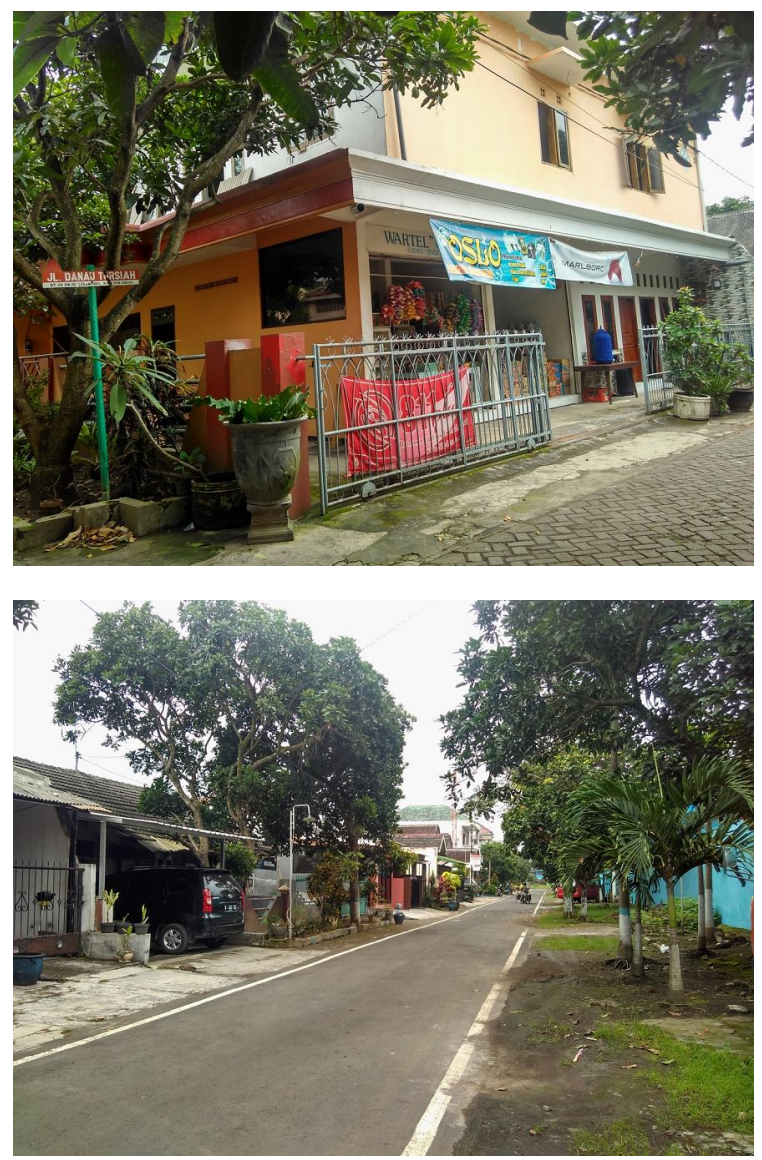

\section{Kearifan Lokal Pada Skala Meso}

A. Penataan Pola dan Cluster Rumah

\section{GUNA LAHAN}

Penggunaan lahan di kawasan sawojajar cenderung berkembang lebih pesat terutama kegiatan perdagangan dan jasa serta permukiman. Selain itu juga terdapat kegiatan pertokoan, rumah makan, bangunan pendidikan, dan ruang terbuka hijau (RTH).
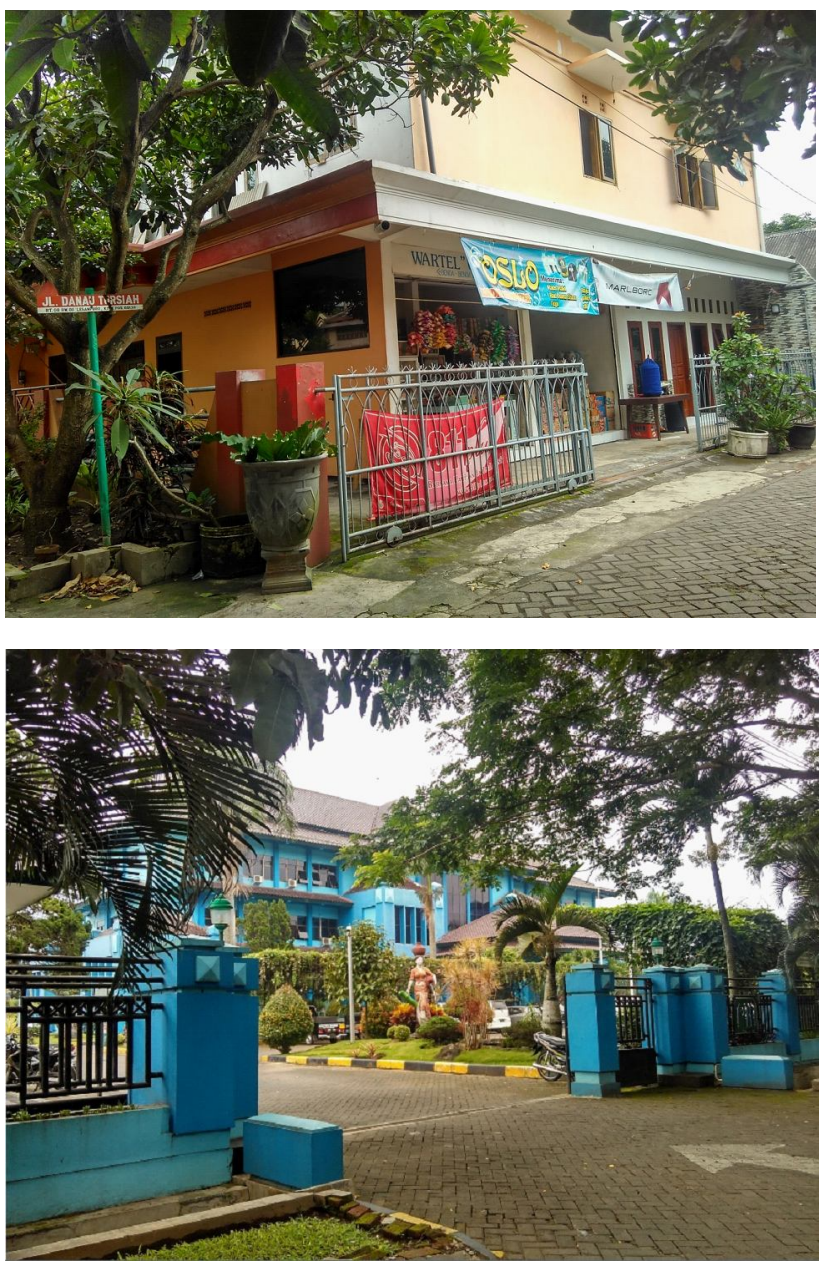

\section{TRANSPORTASI}

Sistem sirkulasi di kawasan studi adalah sistem transportasi darat, yaitu berupa jaringan jalan. Jalan-jalan utama di kawasan studi dibebani oleh lalu lintas antar kawasan permukiman yang merupakan jalan arteri primer dengan intensitas yang tinggi. Selain arteri primer, di wilayah studi juga dilalui jalan arteri sekuder, kolektor dan jalan lingkungan berupa jalan kecil/gang. 

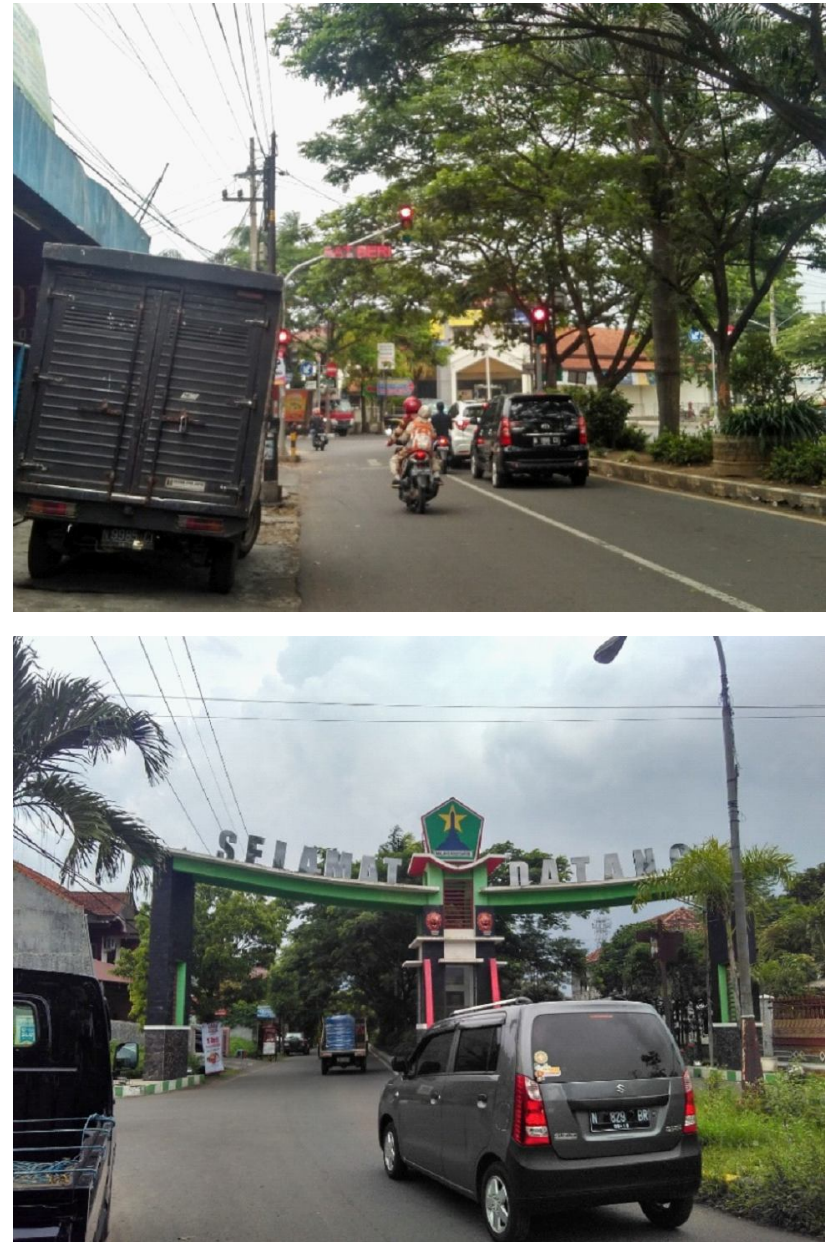

\section{SOSIAL BUDAYA}

Karena pengaruh ekonomi dari tahun ke tahun, munculnya penduduk-penduduk baru yang hanya sekedar menyewa bangunan untuk usaha atau sekaligus menjadikan rumah tersebut menjadi toko dan tidak lagi selalu bergantung pada pekerjaan pada perkantoran di pusat kota.

\section{POLITIK}

Secara aspek politik perubahannya adalah pada sempadan bangunan, dimana sempadan bangunan yang dulunya selalu patuh dengan peraturan dan undang-undang menjadi tidak mematuhi aturan yang ada akibatnya banyak bangunan- bangunan yang tidak berpenghuni contohnya adalah ruko yang berbaris rapi di sudut-sudut permukiman sawojajar.
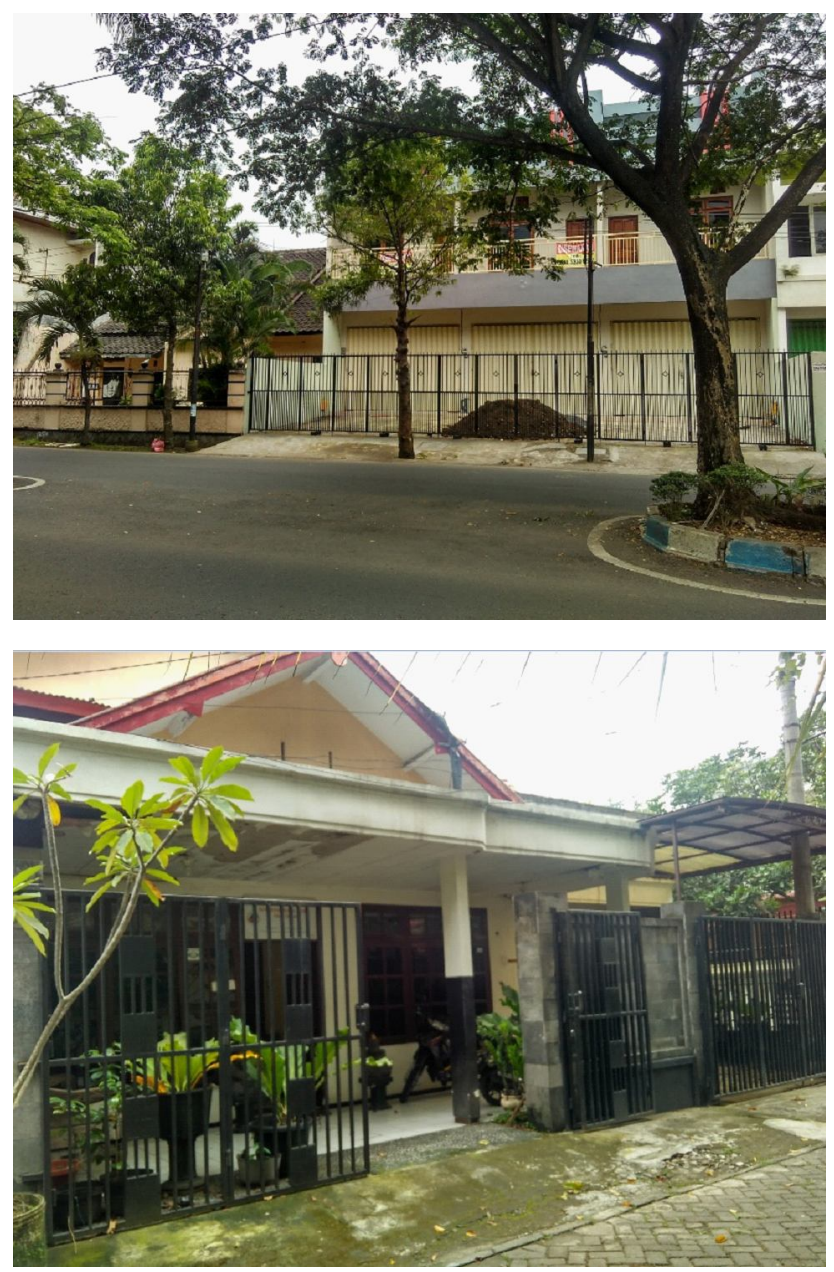

\section{KESIMPULAN}

Dari pembahasan tersebut dapat ditarik kesimpulan bahwa pertumbuhan penduduk di pengaruhi oleh banyaknya keperluan yang ada dari segi aspek fisik dan non-fisik, menyebabkan pesatnya jumlah penduduk akan kebutuhan. Dari segi makro dapat ditarik kesimpulan bahwa dari segi kearifan lokal penduduk setempat rumah yang dahulunya adalah rumah tinggal berallih menjadi rumah yang memiliki pertokoan, selain menunjang 
sosial ekonominya masyarat juga memiliki tambahan akan ekonomi untuk memenuhi kebutuhan.

Tataguna lahan yang ada seharusnya diperuntukan untuk lahan permukiman, sehingga pemerintan dari segi aspek sosial budaya tidak menyesuaikan dengan peta peruntukan lahan dari dinas perkotaan setempat, akibat dari itu RTH(ruang terbuka hijau) disawojajar ini banyak sekali berkurang dan beralih fungsi menjadi tataguna lahan.

Kearifan lokal penduduk setempat secara tidak langsung dipengaruhi oleh adanya saling ketertarikan antara penduduk, yaitu sosial budaya akan berjual di daerah ini, masyarakat kebanyakan yang memiliki pekerjaan sebagai petani dan berkebun berangsur-angsur memiliki toko dan me- ninggalkan pekerjaannya sebagai petani dan memiliki sebuah toko untuk memenuhi kebutuhannya.

\section{REFERENSI}

Antariksa, 2005 jurnalurnal Sains dan Teknologi EMAS, Fakultas Teknik UniversitasKristen Indonesia, Vol. 15, No. 1, Februari2005.hlm. 64-78.ISSN: 08539723

Abdul Hakim dan Endah Setyowati, 2005. Perubahan Kelembagaan Pemerintahan Desa dan

Tantangannnya Terhadap Pengembangan Sumberdaya Aparatur Desa. Malang. Jurnal

Administrasi Publik. Vol. V1/No. 1. 